ARTICULO DE INVESTIGACION

\title{
Evaluación de las características del fruto de huizache (Acacia farnesiana (L.) Willd.) \\ para su posible uso en curtiduría o alimentación animal
}

\section{Evaluation of characteristics of huizache (Acacia farnesiana (L.) Willd.) fruit for potential use in leather tanning or animal feeding}

\author{
Lucía Barrientos-Ramírez¹, J. Jesús Vargas-Radillo1, \\ Antonio Rodríguez-Rivas ${ }^{1}$, Héctor Guillermo Ochoa-Ruíz1, \\ Fernando Navarro-Arzate ${ }^{1}$ y José Zorrilla ${ }^{2}$
}

\begin{abstract}
RESUMEN
El huizache (Acacia farnesiana (L.) Willd.) es una especie silvestre distribuida en el estado de Jalisco y en México, que podría ser utilizada como forraje. Se realizó un estudio para determinar análisis químico proximal (AQP), perfil de aminoácidos y degradabilidad de la materia in situ, en borregos pelibuey fistulados, utilizando el fruto (cáscara y semilla) del huizache, sin tratamiento alguno y con extracción previa de taninos. Los taninos fueron evaluados por los métodos ALCA y número de Stiasny. La semilla cruda presento $23,0 \%$ en proteína, superior al encontrado en cáscara, de $14,9 \%$. Los aminoácidos presentes en mayor proporción fueron histidina, valina, treonina, leucina e isoleucina, mientras que lisina y metionina+cisteína fueron los de menor presencia. La cáscara presentó $9,7 \%$ taninos del tipo condensado y $11,6 \%$ del tipo curtiente, contra $1,8 \%$ y $2,2 \%$ de la semilla. La variable presencia/ausencia de taninos fue la de mayor efecto en los parámetros, por lo que la mayoría de los indicadores en AQP disminuyeron en muestras sin taninos y, por ejemplo, semilla con taninos tuvo $61,7 \%$ en fibra detergente neutra (FDN) y sin taninos $58,1 \%$. Asimismo, la extracción de taninos mejoró la asimilación del material en el rumen de los borregos.
\end{abstract}

PALABRAS CLAVE:

Borregos pelibuey fistulados, composición química proximal, degradabilidad in situ, perfil de aminoácidos, taninos.

\begin{abstract}
Huizache (Acacia farnesiana (L.) Willd.) is a wild species commonly distributed in Jalisco and other states of Mexico, which may be used as forage. A study was performed on the fruit of huizache (husk and seed) in both, untreated samples and samples with pre-extraction of tannin, for the determination of chemical proximal analysis (QPA), aminoacid profile, and in situ degradability, in fistulated pelibuey sheep specimens. Tannins were evaluated using the ALCA method and the Stiasny number technique. QPA analysis showed high protein content in raw seeds of $23,0 \%$, higher than husk content
\end{abstract}


which was $14,9 \%$. Samples showed high concentrations of histidine, valine, threonine, leucine and isoleucine, but low concentrations of lysine and methionine+cysteine. The tannins content was $9,7 \%$ of condensed type and $11,6 \%$ of tannin for tanning in husk, versus $1,8 \%$ and $2,2 \%$ in seed, respectively. The presence/absence of tannin had the greatest effect on the parameters studied. The most of the indicators in PQA decreased in samples without tannins. Seed with tannins showed $61,7 \%$ of neutral detergent fiber (NDF) and seed without tannin had $58,1 \%$, for example. Tannins' extraction improved digestibility into the sheep's rumen.

KEY WORDS:

Pelibuey fistulated sheep, chemical proximal analysis, in situ degradability, aminoacids profile, tannins.

\section{INTRODUCCIÓN}

Las leguminosas son plantas que tienen un papel importante en la alimentación debido a su alto contenido proteico, el cual se fundamenta en la composición de sus aminoácidos constitutivos (Alcántara et al., 1986; Granito et al., 2003). Estos recursos han resuelto las restricciones de alimento en épocas críticas de sequía (Clarke et al., 1989; Hermosillo et al., 2008). A este respecto, las leguminosas se han destacado como un sustituto eficaz a la proteína animal (Famurewa y Raji, 2005). Entre estas especies se encuentra el huizache (Acacia farnesiana (L.) Willd.). En América, esta especie se encuentra distribuida desde el sur de los Estados Unidos hasta Argentina (Gómez et al., 1970; Rojas-Rodríguez y TorresCórdoba, 2012). En México se distribuye en la vertiente del pacífico, desde el sur de Sonora hasta Chiapas, y de forma discontinua en la vertiente atlántica, principalmente en el bosque tropical caducifolio, en climas cálidos y semicálidos (Rzedowski, 1988). El follaje y las vainas podrían aprovecharse como alimento para ganado y cabras de las regiones áridas de México, siendo una alternativa poco estudiada en la alimentación de rumiantes.

En particular, las vainas de huizache se caracterizan por su valor nutricional y podrían ser un material idóneo para ser utilizado como fuente de nutrientes de bajo costo para pequeños rumiantes (Sotelo, 1981; Velázquez et al., 2005). Esto es importante debido a la escasa disponibilidad de nutrientes dentro de los sistemas de producción rural, particularmente en el periodo de estiaje (Velázquez et al., 2011).

Sin embargo, se sabe que esta leguminosa arbustiva contiene taninos, los cuales pueden ser condensados o hidrolizables. Estos compuestos son considerados como agentes antinutricionales (Mueller-Harvey, 2006), que de forma mayoritaria causan efectos desfavorables en el proceso digestivo, aunque en algunos casos este efecto es positivo. Los taninos pueden disminuir la capacidad de degradación de la fibra y la utilización de la proteína en el rumen. Este efecto antinutricional puede provocar una baja aceptabilidad del alimento, pérdida de peso, poca retención de nitrógeno, disminución de la energía metabolizable y de la degradabilidad de la materia seca en el ganado (Barahona et al., 1997; Barry et al., 1999). De igual forma, pueden inactivar las enzimas digestivas de los herbívoros y crear complejos agregados de taninos y proteínas de plantas, los cuales son difíciles de digerir. En particular, los del tipo hidrolizables son potencialmente tóxicos, debido a las sustancias que originan cuando se degradan en el rumen, ya que pueden promover e inhibir la actividad enzimática (Bhat et al.,1998). Por otra parte, se ha publicado que los del tipo condensado son considerados no tóxicos para este tipo de animales, ya que mejoran el desempeño productivo en animales afectados por la parasitosis gastrointestinal (Romero et al., 2000), mientras que a bajas concentraciones 
pueden incrementar el nivel de aminoácidos azufrados que entran al torrente sanguíneo (Cecconello et al., 2003). Sin embargo, pueden producir lesiones en la mucosa intestinal, lo que ocasiona una disminución en la absorción de nutrientes (Reed, 1995; Frutos et al., 2004).

No obstante, la presencia de taninos en la ración alimenticia previene el timpanismo, debido a la disminución en la concentración de proteínas (mencionada con anterioridad) en el rumen (Pereira Filho et al., 2005). Niveles altos de taninos mezclados con especies ricas en nitrógeno soluble mejoran la degradación proteica y la absorción del nitrógeno diluyendo el efecto de los compuestos tóxicos. En cualquier caso, se ha encontrado que el consumo de taninos mayor a $40 \mathrm{~g} / \mathrm{kg}$ resulta nocivo para rumiantes, ya que la ingesta a este nivel provoca la supresión de la membrana de protección de la proteína dietaría en el rumen (Bhat et al., 1998).

Independientemente del efecto del contenido de taninos en el forraje, existen otras alternativas para el aprovechamiento de los mismos, tales como su uso en las industrias farmacéutica, formulación de adhesivos, y de forma tradicional en la curtiduría (Sánchez, 1980; Garro et al.,1997), además de usos biomédicos, elaboración de productos químicos, fabricación de tintas (Pedraza-Bucio y Rutiaga-Quiñones, 2011), adhesivo natural y formación de paneles de madera (Cardoso et al., 2011). En México la industria de la curtiduría se ha desarrollado continuamente hasta ubicarlo entre los diez mayores países productores de pieles, con una aportación de $4 \%$ en la producción mundial dentro de este rubro. La mayor parte de las tenerías se encuentran en la Ciudad de México, Nuevo León, Jalisco y, sobre todo, Guanajuato (Semarnat-INE, 2007). Para una extracción rentable de este tipo de compuestos, el contenido tánico en la especie vegetal debería ser alrededor de $6 \%$ o mayor (Ochoa,1984); incluso, otros autores consideran que dicho contenido debería ser mayor o igual a 10\% (Happich et al., 1954; Pizzani et al., 2006). Existen varios métodos para la evaluación taninos, que pueden ser divididos en colorimétricos, espectrofotométricos, espectroscópicos, gravimétricos, precipitación proteica y mixtos. En relación con los métodos colorimétricos, que utilizan espectrometría UV-Visible, destacan el método de Folin-Denis (Waterman y Mole, 1994; Vieira et al., 2011), en el cual los resultados se expresan como ácido tánico; o el método $\mathrm{MV}-\mathrm{HCl}$ establecido por Burns (1971) específico para taninos condesados, que utiliza metanol, vainillina y $\mathrm{HCl}$, expresando los resultados en equivalentes de catequina. Por otra parte, dentro de los métodos gravimétricos, se puede mencionar el método del número de Stiasny o Índice de Stiasny-SI (Gnamm, 1949; Paes et al., 2010) y el método ALCA de la American Leather Chemist's Association (ALCA, 1970; Honorato y Hernández, 1998). Stiasny es un método relativamente rápido y sencillo que evalúa taninos condensados, mientras que el método ALCA es un método clásico usado en la industria del cuero que evalúa taninos curtientes (condensados e hidrolizables) por medio de polvos de piel cromados

El huizache contiene aminoácidos y proteínas en semilla y cáscara, así como taninos tanto en hojas (Ephraim et al., 2005) como en corteza y fruto, por lo que podría ser una opción en el mercado forrajero, usos alternativos de taninos y sector de la curtiduría.

\section{OBJETIVOS}

Evaluar la viabilidad de uso de semilla y cáscara de la vaina de huizache libre de 
taninos, como fuente alimentaria, por medio de la determinación de su composición química, perfil de aminoácidos y degradabilidad en borregos pelibuey fistulados. Cuantificar los taninos extraídos como un posible subproducto útil para la industria de la curtiduría.

\section{METODOLOGÍA}

Se colectaron nueve especímenes de Acacia farnesiana en el municipio de Autlán de Navarro, Jalisco, México. La región se localiza en la costa sur del estado, a 192 km al suroeste de Guadalajara, sobre la sierra de Amula, y a una altitud de 925 msnm. En esta región el clima es semiseco y semicálido, sin cambio térmico invernal bien definido. Los especímenes colectados fueron clasificados por personal del herbario del Instituto de Botánica de la Universidad de Guadalajara, IBUG (número de registro del ejemplar 164764), donde se depositaron. Se muestreó el fruto de los especímenes colectados, se separó manualmente la semilla y la cáscara, y se mezclaron por separado para tener una muestra representativa de cada una.

Las semillas y cáscara de huizache se deshidrataron a $60{ }^{\circ} \mathrm{C}$ durante $72 \mathrm{~h}$ en estufa de aire de tiro forzado. Las muestras se pulverizaron en un molino de martillo de aspas Retsch-GmbH con criba con perforaciones de $0,5 \mathrm{~mm}$.

Se evaluó el contenido de proteína cruda, grasa, cenizas y elementos libres de nitrógeno (ELN) aplicando la metodología de la Association of Official Analytical Chemists (AOAC, 1990), en muestras con taninos y sin taninos, así como de fibra ácido detergente (FDA) y fibra detergente neutra (FDN), utilizando las técnicas publicadas por Van Soest (1963). El contenido de lignina se realizó por el método publicado por Tejada (1985).
El análisis de aminoácidos se realizó mediante la técnica empleada por Urribarri et al. (2004), por medio de Cromatografía Líquida de Alta Resolución (HPLC), utilizando un equipo marca Shimadzu con detector UV a $254 \mathrm{~nm}$ y una columna $\mathrm{C}_{18}$ fase reversa Pico Tag ${ }^{\mathrm{TM}}$ Waters $(300 \mathrm{~mm} \times 3,9 \mathrm{~mm})$. Para este análisis, las muestras se desgrasaron y posteriormente se hidrolizaron. Para este propósito, $50 \mathrm{mg}$ de harina de semilla de huizache se trataron con $20 \mathrm{~mL}$ de una solución $6 \mathrm{~N}$ de $\mathrm{HCl}$ en tubos de cierre hermético y medio inerte (desplazamiento del aire con nitrógeno). Los tubos se colocaron en una estufa a $45^{\circ} \mathrm{C}$ por $4 \mathrm{~h}$ y se neutralizaron con una solución $6 \mathrm{~N}$ de $\mathrm{NaOH}$. La suspensión neutralizada se filtró a través de papel filtro whatman número 1. El material se aforó a $100 \mathrm{~mL}$ con buffer de citrato de sodio, y se filtró nuevamente utilizando membranas millipore de nylon con porosidad de 0,2 $\mu \mathrm{m}$. Para la detección en HPLC se aplicó a la muestra una solución fluorescente de o-ftalaldehído (OPA). El perfil de aminoácidos, además de los aminoácidos limitantes, se determinó utilizando como referencia los patrones establecidos por la FAO/WHO (1991).

El estudio de digestibilidad o degradabilidad in situ (desaparición de la materia seca) antes y después de la extracción de taninos, se realizó en dos borregos machos de raza pelibuey. El promedio de edad y peso de éstos animales fue de 1 año y $36 \mathrm{~kg}$. A cada especimen se le colocó una fístula a nivel ruminal. Los borregos fueron sometidos a un periodo de adaptación de 15 días, y se aplicó una dieta consistente en una ración de $20 \%$ de harina de huizache, adicionada con sorgo, soya y rastrojo de maíz. Se incubaron en el rumen de los borregos $5 \mathrm{~g}$ de harina de huizache con y sin taninos, por $72 \mathrm{~h}$. Cada incubación se realizó por triplicado, utilizando bolsas de nylon estandarizadas (1500 perfora- 
ciones $/ \mathrm{cm}^{2}$ ). Las bolsas se retiraron, lavaron y deshidrataron. Se analizó el contenido de proteína cruda y materia orgánica de acuerdo con la técnica publicada por Tejada (1985).

Para la evaluación de taninos se aplicó el índice de Stiasny y el método de polvos de piel. El número de Stiasny mide la reactividad de los extraíbles polifenólicos (taninos condensados) en presencia de formaldehido: $10 \mathrm{~g}$ de muestra (semilla o cáscara) se mezclaron con $150 \mathrm{~mL}$ de agua destilada y se agitaron por $24 \mathrm{~h}$, a temperatura ambiente, y se midió el $\mathrm{pH}$ final del extracto tánico. A una muestra de $50 \mathrm{~mL}$ del extracto se agregaron $5 \mathrm{~mL}$ de $\mathrm{HCl}$ concentrado y $10 \mathrm{~mL}$ de solución de formaldehído al $40 \%$. La mezcla se mantuvo en ebullición bajo reflujo por 30 minutos obteniendo un precipitado tánico, el cual se separó de la fase acuosa mediante filtración con vacío utilizando un filtro gooch de mediana porosidad previamente secado y tarado. El precipitado obtenido se lavó con agua destilada y se secó en estufa por dos horas a $120^{\circ} \mathrm{C}$. El material resultante se enfrió en un desecador y se peso. Se calculó como la cantidad de precipitado tanino-formaldehído seco formado $\left(\mathrm{M}_{2}\right)$ respecto al peso de la sustancia seca presente en la solución (en este caso de $50 \mathrm{~mL}$ ) de la muestra tratada $\left(M_{1}\right)$, expresado como porcentaje,

$$
N S=\frac{M_{2}}{M_{1}} \cdot 100
$$

La cantidad de taninos presente en la muestra se obtuvo al multiplicar NS por los sólidos solubles totales (Paes et al., 2010, Ec. 2),

$$
T=\frac{S S T \cdot N S}{100}
$$

El segundo método, ALCA, consistió en tomar $75 \mathrm{~mL}$ del extracto tánico en un matraz Erlenmeyer de $300 \mathrm{~mL}$. A esta suspensión se le añadieron $6,5 \mathrm{~g}$ de polvo de piel cromado (Merck), utilizados en la determinación de curtientes, y se agitó de forma enérgica durante 10 minutos. El material se filtró y se agregó caolín. Se filtró una vez más hasta que la solución quedó clara. El filtrado (material no curtiente) se secó en una estufa Felisa a $100^{\circ} \mathrm{C}$ y se determinó el peso del material residual. Éste se relacionó con el peso inicial extraído base seca. El material residual se denomina "sustancia no tánica", correspondiente al material no curtiente. El contenido de taninos (material absorbible por el polvo de cuero) se determinó por diferencia de los sólidos solubles totales y la sustancia no tánica. Los sólidos solubles totales (SST), se cuantificaron utilizando $100 \mathrm{~mL}$ del extracto tánico filtrado, los cuales se llevaron a sequedad total en un horno a $100{ }^{\circ} \mathrm{C}$ para pesar el residuo seco, y se relacionó este valor con el peso del volumen utilizado (Ec. 3),

$$
S S T=\frac{M_{i}-M_{f}}{M_{f}} \cdot 100
$$

donde

$M_{i}$ : masa seca de la muestra, $\mathrm{g}$

$M_{f}$ : masa seca del extracto, $g$

\section{Diseño experimental y análisis estadístico}

Para evaluar la calidad forrajera se aplicó un diseño estadístico comparativo, cuyas variables experimentales fueron la presencia o ausencia de taninos tanto en semilla como en cáscara, mientras que las variables de respuesta fueron los parámetros de composición química proximal, aminoácidos y degradabilidad de la materia. El contenido de taninos se hizo en semilla y cáscara, también de 
forma comparativa. Las pruebas se hicieron por triplicado (excepto los aminoácidos, cuyas determinaciones fueron unitarias). La prueba estadística fue hecha por el método ANOVA de contraste post-hoc, mientras que para la comparación de medias entre tratamientos se eligió la prueba de Tukey (1949). Se utilizó el software Statgraphics Centurion XV.

\section{RESULTADOS Y DISCUSIÓN}

La composición química proximal en semilla y cáscara de huizache se presenta en la tabla 1. ANOVA indica que la presencia $O$ ausencia de taninos $(p=0,0869)$ estadísticamente es más significativo que la parte (semilla o cáscara) analizada ( $p=0,3783)$. El contenido de proteína cruda en la semilla fue de $23,0 \%$ en el material con taninos, disminu- yendo a $17,4 \%$ en la muestra sin taninos. En el caso de la cáscara, se observaron valores de $14,9 \%$ y $10,1 \%$, respectivamente. Estos valores se consideran altos en relación con los contenidos registrados en algunas otras leguminosas, tales como Acacia acatlensis con $13,22 \%$ y Acacia macrocantha con $13,75 \%$ de proteína cruda en base seca (Román et al., 2008). Por otra parte, el análisis de FDN mostró que la semilla con taninos tuvo un contenido ligeramente mayor, con $61,7 \%$, que la semilla sin taninos, la cual presentó, $58,1 \%$. En cáscara, el contenido de FDN pasó de $59,3 \%$ a $33,1 \%$ después de la extracción de taninos, lo que significa una reducción de $26,2 \%$. Respecto a FDA, cáscara con taninos con $66,0 \%$, arrojó $3,8 \%$ más que la FDA de las semillas con taninos $(62,2 \%)$. Estos valores son consistentes con concentraciones de FDA encontradas en especies similares tales como Acacia glomerosa, con $66,41 \%$

Tabla 1. Composición químico proximal en semilla y cáscara de huizache (g/100 $\mathrm{g}$ base seca*).

\begin{tabular}{lcccc}
\hline $\begin{array}{l}\text { Parámetro } \\
(\%)\end{array}$ & \multicolumn{3}{c}{ Semilla } & Cáscara \\
\hline & $\begin{array}{c}\text { Con taninos } \\
\bar{x} \pm s\end{array}$ & $\begin{array}{c}\text { Sin taninos } \\
\bar{x} \pm s\end{array}$ & $\begin{array}{c}\text { Con taninos } \\
\bar{x} \pm s\end{array}$ & $\begin{array}{c}\text { Sin taninos } \\
\bar{x} \pm s\end{array}$ \\
\hline Materia seca & $88,9 \pm 0,30 \mathrm{~d}$ & $92,3 \pm 0,100 \mathrm{a}$ & $90,6 \pm 0,11 \mathrm{c}$ & $91,2 \pm 0,11 \mathrm{~b}$ \\
Proteína cruda & $23,0 \pm 0,10 \mathrm{a}$ & $17,4 \pm 0,17 \mathrm{~b}$ & $14,9 \pm 0,10 \mathrm{c}$ & $10,1 \pm 0,11 \mathrm{~d}$ \\
Extracto etéreo & $2,5 \pm 0,06 \mathrm{a}$ & $2,4 \pm 0,35 \mathrm{a}$ & $1,4 \pm 0,06 \mathrm{~b}$ & $1,2 \pm 0,15 \mathrm{~b}$ \\
E.L.N. & $54,3 \pm 0,17 \mathrm{c}$ & $54,5 \pm 0,38 \mathrm{c}$ & $64,2 \pm 0,25 \mathrm{~b}$ & $66,1 \pm 0,11 \mathrm{a}$ \\
F.D.N. & $61,7 \pm 0,26 \mathrm{a}$ & $58,1 \pm 0,23 \mathrm{c}$ & $59,3 \pm 0,06 \mathrm{~b}$ & $33,1 \pm 0,23 \mathrm{~d}$ \\
F.D.A. & $62,2 \pm 0,30 \mathrm{~b}$ & $58,5 \pm 0,42 \mathrm{c}$ & $66,0 \pm 0,06 \mathrm{a}$ & $53,0 \pm 0,29 \mathrm{~d}$ \\
Lignina & $14,1 \pm 0,11 \mathrm{a}$ & $11,0 \pm 0,15 \mathrm{c}$ & $13,0 \pm 0,11 \mathrm{~b}$ & $8,8 \pm 0,11 \mathrm{~d}$ \\
Cenizas & $1,5 \pm 0,06 \mathrm{a}$ & $1,8 \pm 0,15 \mathrm{a}$ & $1,1 \pm 0,06 \mathrm{~b}$ & $1,0 \pm 0,17 \mathrm{~b}$ \\
\hline
\end{tabular}

Notas:

Todos los parámetros presentados fueron evaluados por triplicado, $\bar{x}=$ media, $s=$ desviación estándar

$a, b, c$ Medias con diferente literal en la misma fila difieren significativamente $(p<0,05)$

E. L. N. = elementos libres de nitrógeno

F. D. N. = fibra detergente neutra

F. D. A. = fibra detergente ácida

*g.b.s. = gramos base seca 
(Pizzani et al., 2006), así como para contenidos de FDN de $64,90 \%$ para Acacia acatlensis y Acacia macracantha (Román et al., 2008).

El perfil de aminoácidos se muestra en la tabla 2. La comparación de columnas mostró que no existe diferencia estadística significativa entre los aminoácidos de semilla y cáscara $(p=0,9226)$. Los aminoácidos Histidina (His), valina (Val), treonina (Treo) y leucina (Leu) fueron superiores al requerimiento esencial de aminoácidos recomendados por la FAO. Lo anterior se reflejó como un valor alto de calificación química. Por otra parte, también se observaron valores inferiores a estos estándares, de lisina (Lis) y metionina+cisteina (Met+Cis), por lo que estos fueron los aminoácidos limitantes en semilla y cáscara. La degradabilidad y la biodisponibilidad de los aminoácidos proteicos son factores importantes que caracterizan la calidad de ésta (Hsu et al., 1977; Suman et al., 1992). En su papel de sustancias esenciales de la vida, los aminoácidos son nutrientes críticos en cualquier formulación dietética animal. De aquí la importancia de localidad y cantidad de los aminoácidos presentes en las materias primas utili-

Tabla 2. Contenido (g/16g de N) de aminoácidos en semilla y cáscara de huizache.

\begin{tabular}{|c|c|c|c|c|c|}
\hline \multirow[t]{2}{*}{ Aminoácido } & \multicolumn{2}{|c|}{ Muestra } & \multirow{2}{*}{$\begin{array}{l}\text { Requerimiento esencial } \\
\text { de aminoácidos } \\
\text { (2-5 años })\end{array}$} & \multicolumn{2}{|c|}{ Calificación química (C. Q.) } \\
\hline & Semilla & Cáscara & & Semilla & Cáscara \\
\hline ASP & 10,7 & 12,9 & --- & --- & --- \\
\hline GLU & 12,2 & 11,6 & --- & --- & --- \\
\hline SER & 9,8 & 9,4 & --- & --- & --- \\
\hline GLI & 11,3 & 7,3 & --- & --- & --- \\
\hline HIS & 2,6 & 2,0 & 1,9 & 136,8 & 105,3 \\
\hline ARG & 6,3 & 3,4 & --- & --- & --- \\
\hline TRE & 4,6 & 4,7 & 3,4 & 135,0 & 138,2 \\
\hline ALA & 8,0 & 9,3 & --- & --- & --- \\
\hline PRO & 7,2 & 9,0 & --- & --- & --- \\
\hline TIR & 3,2 & 4,0 & --- & --- & --- \\
\hline VAL & 5,9 & 8,2 & 3,5 & 168,6 & 234,3 \\
\hline MET+CIS & 0,8 & N.D. & 3,4 & 23,5 & N.D. \\
\hline ILE & 3,9 & 4,5 & --- & --- & --- \\
\hline LEU & 7,8 & 7,7 & 6,6 & 118,2 & 116,7 \\
\hline ISO-LEU & 3,6 & 4,1 & 2,8 & 128,6 & 146,4 \\
\hline FEN+TIR & 5,7 & 7,4 & 6,3 & 90,5 & 117,5 \\
\hline LIS & 1,9 & 2,0 & 5,0 & 37,6 & 39,6 \\
\hline
\end{tabular}

Notas:

N. D. = no detectado

$$
\begin{aligned}
\text { Calificación quimica }= & \begin{array}{l}
g \cdot \text { de } \cdot \text { aminoácido en muestra } \\
g \text { de aminoácido en patrón }
\end{array} \text { 吕O } \\
& \text { WHO }
\end{aligned}
$$


zadas en la elaboración de alimentos balanceados para animales.

En relación con la degradabilidad de la materia (Tabla 3 ), el resultado experimental fue satisfactorio, de acuerdo con los criterios sobre el parámetro de degradabilidad (DMS $\geq 50 \%$ ), establecido por Pizzani et al. (2006). Se obtuvieron valores de DMS superiores a $60 \%$, excepto en la cáscara con taninos que arrojó un valor de 59,2\%. Asimismo, el análisis de varianza expresó diferencia significativa entre las variables $(p=0,0279)$, relativo a la presencia $o$ ausencia de taninos, pero también relativo a la muestra probada, semilla o cáscara. En la tabla se observa que la degradabilidad in situ se incrementó en el material sin taninos, tanto en semilla como en cáscara; la semilla registró un incremento en todos los parámetros estudiados, mientras que la cáscara presentó un incremento en DMS, DMO, DFDN, y DFDA, así como también una ligera disminución en DPC. Es de destacar el significativo aumento de DFDN tanto en semilla como en cáscara, y que la cáscara sin taninos presentó el mayor índice $(93,5 \%)$. Este comportamiento es similar a los resultados obtenidos por Valerio (1994), quien encontró que al disminuir la cantidad de taninos ensilados de muestras de semillas, se incrementó la digestibilidad en rumiantes. El comportamiento del material de huizache analizado, sugiere un elevado potencial de utilización como alimento. Algunos autores (Cecconello et al., 2003; Velázquez et al., 2005) mencionan que las vainas secas y molidas del huizache pueden utilizarse en las dietas de ganado lanar en crecimiento, hasta en $40 \%$ de inclusión en mezclas con rastrojo de maíz molido sin ocasionar trastornos clínicos.

Tabla 3. Degradabilidad in situ de la materia seca, materia orgánica y proteína cruda, para muestras de semilla y cáscara de huizache.

\begin{tabular}{lcccc}
\hline Parámetro (\%) & \multicolumn{4}{c}{ Muestra } \\
& \multicolumn{3}{c}{ Semilla } & \multicolumn{2}{c}{ Cáscara } \\
& $\bar{x} \pm s$ & $\begin{array}{c}\text { Sin taninos } \\
\bar{x} \pm s\end{array}$ & $\begin{array}{c}\text { Con taninos } \\
\bar{x} \pm s\end{array}$ & $\begin{array}{c}\text { Sin taninos } \\
\bar{x} \pm s\end{array}$ \\
\hline DMS & $60,9 \pm 0,06 \mathrm{c}$ & $70,0 \pm 0,06 \mathrm{a}$ & $59,2 \pm 0,20 \mathrm{~d}$ & $61,8 \pm 0,12 \mathrm{~b}$ \\
DMO & $61,0 \pm 0,72 \mathrm{c}$ & $70,7 \pm 0,11 \mathrm{a}$ & $62,0 \pm 0,56 \mathrm{c}$ & $68,9 \pm 0,47 \mathrm{~b}$ \\
DPC & $67,7 \pm 0,17 \mathrm{c}$ & $71,6 \pm 0,05 \mathrm{a}$ & $72,1 \pm 0,36 \mathrm{a}$ & $70,9 \pm 0,29 \mathrm{~b}$ \\
DFDN & $54,9 \pm 0,26 \mathrm{~d}$ & $83,2 \pm 0,57 \mathrm{~b}$ & $75,6 \pm 0,26 \mathrm{c}$ & $93,5 \pm 0,26 \mathrm{a}$ \\
DFDA & $52,5 \pm 0,17 \mathrm{~d}$ & $74,7 \pm 0,10 \mathrm{~b}$ & $60,7 \pm 0,30 \mathrm{c}$ & $77,1 \pm 0,17 \mathrm{a}$ \\
\hline
\end{tabular}

Notas:

Todos los parámetros mostrados fueron evaluados por triplicado, $\bar{x}=$ media, $s=$ desviación estándar

$a, b, c$ Medias con diferente literal en la misma fila difieren significativamente $(p<0,05)$

DMS = digestibilidad de la materia seca

$\mathrm{DMO}=$ digestibilidad de la materia orgánica

DPC = digestibilidad de la proteína cruda

DFDN = digestibilidad de la fibra detergente neutra

DFDA = digestibilidad de la fibra detergente ácida

Todos los parámetros reportados sobre base seca 
La tabla 4 expresa los resultados de los análisis de contenido en taninos. Existe diferencia estadística significativa entre taninos en semilla y taninos en cáscara $(p=0,0124)$. La cáscara presentó un contenido considerablemente mayor de taninos condensados (taninos por reacción de Stiasny de 9,7), así como $11,6 \%$ de taninos hidrolizables y condensados (denominados proantocianidinas o catéquicos), a través de las pruebas realizadas con polvos de piel (método ALCA). La presencia de taninos se confirmó mediante una prueba colorimétrica, resultante de la reacción del extracto de agua de la cáscara con $\mathrm{SO}_{4} \mathrm{Fe}$ y acetato de amonio. Este contenido en taninos curtientes en cáscara es mayor que los registrados en otras especies tales como Acacia macrantha $(2,40 \%)$, Enterolobium cyclocarpum (1,18\%), Pithecellobium dulce (1,01\%), Caesalpinia coriria (5,25\%) y Lysiloma divaricata (6,47\%) (Pizzani et al., 2006). Respecto a la semilla, ésta presentó considerablemente menos contenido de taninos condensados $(1,8 \%)$, y de taninos curtientes $(2,2 \%)$.

\section{CONCLUSIONES}

El huizache (Acacia farnesiana) tiene un alto valor nutricional por su contenido en proteína cruda (23\%) y la concentración de aminoácidos esenciales, valorada tanto en semilla como en cáscara. Es un recurso potencialmente utilizable como una opción alimenticia de bajo costo para ganado ovino aún en épocas críticas de sequía, para formular dietas base suplementarias, haciendo una mezcla balanceada con gramíneas, las cuales suministrarían los aminoácidos azufrados deficitarios en las leguminosas.

Por otra parte, aunque la presencia de taninos no es un impedimento para el uso forrajero del fruto de esta especie, debido a que la mayor concentración es en follaje y corteza, se sugiere una extracción previa de los mismos, ya que su eliminación mejora la digestibilidad del forraje, pero además, los taninos podrían ser usados como un subproducto útil en la industria de las pieles como curtiente orgánico, o en las industrias farmacéu-

Tabla 4. Contenido de taninos en semilla y cáscara de huizache.

\begin{tabular}{lccc}
\hline Parámetro & Unidad & Semilla & Cáscara \\
\hline Humedad & $(\%)$ & $12,6 \pm 0,11 \mathrm{~b}$ & $13,0 \pm 0,11 \mathrm{a}$ \\
Solubilidad: agua fría & $(\%)$ & $6,9 \pm 0,10 \mathrm{a}$ & $4,0 \pm 0,11 \mathrm{~b}$ \\
$\quad$ agua caliente & $(\%)$ & $6,3 \pm 0,17 \mathrm{a}$ & $6,2 \pm 0,17 \mathrm{a}$ \\
Extracto total & $(\%)$ & $22,4 \pm 0,20 \mathrm{~b}$ & $24,6 \pm 0,17 \mathrm{a}$ \\
Sólidos solubles totales (SST) & $(\%)$ & $20,4 \pm 0,20 \mathrm{~b}$ & $22,6 \pm 0,15 \mathrm{a}$ \\
Taninos (polvos de piel) & $(\%)$ & $2,2 \pm 0,21 \mathrm{~b}$ & $11,6 \pm 0,17 \mathrm{a}$ \\
Taninos (Índice de Stiasny) & $(\%)$ & $1,8 \pm 0,25 \mathrm{~b}$ & $9,7 \pm 0,23 \mathrm{a}$ \\
Reacción de coloración & adimensional & Negativo & Positivo \\
pH & adimensional & 4,0 & 4,5 \\
\hline
\end{tabular}

Notas:

Todos los parámetros presentados fueron evaluados por triplicado, $\bar{x}=$ media, $s=$ desviación estándar

$a, b, c$ Medias con diferente literal en la misma fila difieren significativamente $(p<0,05)$ 
tica, química o vitivinícola, lo cual aumentaría su valor agregado.

El huizache es un recurso vegetal de amplia biodisponibilidad que no ha sido totalmente aprovechado, que podría ser una opción de bajo costo para alimentar ganado en épocas críticas.

\section{REFERENCIAS}

ALCA. 1970. Methods of Sampling and Analysis. American Leather Chemists Association, Cincinnati, Ohio. 28 p.

Alcántara, S.E., E.S. Ochoa, B.A. Aguilera y F. Perezgil. 1986. Huizache (Acacia-farnesiana, Willd) as an alternative resource in goat feeding. Archivos Latinoamericanos de Nutrición 36(1):135-151.

AOAC. 1990. Official Methods of Analysis of the Association of Official Analytical Chemists. Association of Official Analytical Chemists, Inc., Arlington, VA. 15th edition (ed. K. Helrich).

Barahona, R., C.E. Lascano, R.C. Cochran, J.L. Morril y E.C. Titgemeyer. 1997. Condensed tannins in tropical legumes: Concentration, astringency and effects on the nutrition of ruminants. 18 Congreso internacional de pastizales. Winnipeg, Canadá.

Barry, T.N. y W.C. McNabb. 1999. The implications of condensed tannins on the nutritive value of temperate forages fed to ruminants. British Journal of Nutrition 81(4):263-272.

Bhat, T.K., B. Singh y O.P. Sharma. 1998. Microbial degradation of tannins - A current perspective. Biodegradation 9(5):343-357.
Cardoso, M.C., R.C.C. Costa, B.C. Silva y G.L. Oliveira. 2011. Tannin extraction from the bark of Pinus oocarpa var. oocarpa with sodium carbonate and sodium bisulfite. Floresta e Ambiente 18(1):1-8

Burns, R.E. 1971. Method for estimation of tannin in grain sorghum. Agron. J. 63:511-512.

Cecconello, G., M. Benezra y N.E. Obispo. 2003. Composición química y degradabilidad ruminal de los frutos de algunas especies forrajeras leñosas de un bosque seco tropical. Zootecnia Trop. 21(2):149-165.

Clarke, H.D., D.S. Seigler y J.E. Ebinger. 1989. Acacia farnesiana (Fabaceae, Mimosoideae) and related species from Mexico, the southwestern United States, and the Caribbean. Systematic Botany 14(4):549-564.

Ephraim, E., A. Odenyo y M. Ashenafi. 2005. Isolation and characterization of tannin-degrading bacteria from faecal samples of some wild ruminants in Ethiopia. Animal Feed Science and Technology 118 (3-4):243-253.

Famurewa J., A.V. y A.O. Raji. 2005. Parameters affecting milling qualities of undefatted soybeans (Glycine max L. Merill) (1) Selected thermal treatment. Int J Food Eng 1:1.

FAO/WHO. 1991. Protein Quality evaluation, Report of a joint FAO/WHO expert consultation. (FAO food and Nutrition Paper No 51). F. A. A. Organization. Roma, Italia.

Frutos, P., G. Hervás, F.J. Giráldez y R. Mantecón. 2004. Review. Tannins and ruminant nutrition. Spanish 
Journal of Agricultural Research 2(2):191-202.

Gnamm, H. 1949. Die gerbstaffe und bermittel. Stuttgart, Germany. p:81-85.

Garro, G.J., B. Riedl y A.H. Conner. 1997. Analytical studies on tara tannins. Holzforschung 51(3):235-243.

Gómez, L.F., J. Signoret Poillon y M.D.C. Abuín Moreiras. 1970. Mezquites y huizaches: algunos aspectos de la economía, ecología y taxonomía de los géneros Prosopis y Acacia en México. Ediciones del Instituto Mexicano de Recursos Naturales Renovables, A.C. México, D.F.

Granito, M., A. Torres y M. Guerra. 2003. Desarrollo y evaluación de una pasta a base de trigo, maíz, yuca y frijol. Interciencia 28(7):372-379.

Happich, M.L., C.W. Beebe y J.S. Rogers. 1954. Tannin evaluation of one hundred sixty-three species of plants. J. Amer. Leather Chem. Assoc. 49:760-773.

Hermosillo G., Y., J. Aguirre O., R.A. Rodríguez, C. Ortega A., A. Gómez G. y R. Magaña M. 2008. Métodos inductivos para maximizar la germinación de semilla de germoplasma nativo en vivero para sistemas silvopastoriles en Nayarit, México. Zooctecnia Trop. 26(3):355-358.

Honorato S., J.A. y J. Hernández P. 1998. Determinación de componentes químicos de la madera de cinco especies de encino del estado de Puebla. Madera y Bosques 4(2):79-93.

Hsu, H.N., D.L. Vavak, L.D. Satterlee y G.A. Miller. 1977. A multienzyme technique for estimating protein digestibility. Journals of Food Science 42:1269-1271.

Mueller-Harvey, I. 2006. Unravelling the conundrum of tannins in animal nutrition and health. Journal of the Science of Food and Agriculture 86(13):2010-2037.

Ochoa Esquivel, S. 1984. Uso potencial del ensilaje de huizache, Acacia farnesiana $L$. Willd en la alimentación de la cabra. Facultad de Medicina Veterinaria y Zootecnia. México, D.F., Universidad Nacional Autónoma de México. M.V.Z.: 66.

Paes, J.B., G.M. Santana, T.K. Barbosa de Azevedo, R. De Medeiros Morais y J.T. Calixto Júnior. 2010. Tannic substances present in several parts of Anadenanthera colubrina (Vell.) Brenan. var. cebil (Gris.) Alts.) tree. Sci. For., Piracicaba 38(87):441-447.

Pedraza-Bucio, F.E. y J.G. RutiagaQuiñones. 2011. Extracto tánico de la madera de palo de Brasil. Conciencia Tecnológica 42:36-41.

Pereira Filho, J.M., E.L.A.K. Vieira, A.M.A. Silva, M.F. Cezar y P.M.G. Beelen. 2005. Correlação entre o teor de tanino e a degradabilidade ruminal da matéria seca e proteína bruta do feno de jurema-preta (Mimosa tenuiflora Wild) tratada com hidróxido de sódio. Livestock Research for Rural Development 17(8) Art. 91.

Pizzani, P., I. Matute y G. Martino. 2006. Composición fitoquímica y nutricional de algunos frutos de árboles de interés forrajero de los llanos centrales de Venezuela. Rev. Fac. Cienc. Vet. 47(2):105-113. 
Reed, J.D. 1995. Nutritional toxicology of tannins and related polyphenols in forage legumes. Journal of Animal Science 73(5):1516-1528.

Rojas-Rodríguez, F. y G. Torres-Córdoba. 2012. Árboles del valle central de Costa Rica: reproducción, aromo (Acacia farnesiana), Revista Forestal Mesoamericana Kurú (Costa Rica) 9(22):66-67.

Román Miranda, M.L., J.M. Palma, J. Zorrilla, A. Mora y A. Gallegos. 2008. In situ dry matter degradability of flour fruit of guacima, guazuma ulmifolia, with fruit diets from tree species. Zootecnia Tropical 26(3): 227-230.

Romero Lara, C.E., J.M Palma García y L. Juan. 2000. Influencia del pastoreo en la concentracion de fenoles totales y taninos condensados en Gliricidia sepium en el tropico seco. Livestock Research for Rural Development 12(4):1-9.

Rzedowski, J. 1988. Análisis de la distribución geográfica del complejo Prosopis (Leguminosae, Mimosoideae) en Norteamérica. Acta Bot. Mex. 3:7-19.

Sánchez, O. 1980. La flora del Valle de México. $8^{a}$ ed. Herrero. México.

Semarnat, Instituto Nacional de Ecología (INE). 2007. INE.gob.mx.

Sotelo, A. 1981. Leguminosas silvestres, reserva de proteínas para alimentación del futuro. Inf. Científica Tecnol. 3:28-34.

Suman, C.N., P.V. Monterio, G. Ramachandra y L. Sudharshana. 1992. In vitro enzyme hydrolysis of the storage proteins of japanese barn- yard millet (Echinochloa frumentacea). Journal of Science of Food and Agriculture 58(4):505-509.

Tejada de Hernández, I. 1985. Manual de laboratorio para análisis de ingredientes utilizados en la alimentación animal. México, D.F. p. 387.

Tukey, J.W. 1949. Comparing individual means in the analysis of variance. Biometrics 5:99-114.

Urribarrí C.,L., A. Ferrer O. y A. Colina. 2004. Extracción y precipitación de las proteínas solubles del pasto elefante enano (Pennisetum purpureum Schum cv. Mott). Rev. Fac. Agron (LUZ) 21:264-275.

Valerio, S. 1994. Contenido de taninos y digestibilidad in vitro de algunos forrajes tropicales. Agroforestería en las Américas 1(3):10-13.

Van Soest, P.J. 1963. Use of detergents in the analysis of fibrous feeds. II. A rapid method for the determination of fiber and lignin. J. Ass. Offic. Agr. Chem. 46:829-835.

Velázquez, A.J., R. Perezgrovas, M.E. Velasco, L. Zaragoza y G. Rodríguez. 2005. "Evaluación de vainas de quebracho (Acacia farnesiana) en Alimentación de Ganado lanar. Archivos de Zootecnia 54(206207):535-540.

Velázquez, A.J., M. González, J. Bórquez, I.A. Domínguez y R. Perezgrovas. 2011. Composición química $y$ producción de gas in vitro de dietas con vainas de Acacia farnesiana. Arch. Zootec. 60: 1-9.

Vieira, M.C., R.C.C. Lelis, B.C. Silva y G.L. Oliveira. 2011. Tannin extraction from the bark of Pinus oocarpa var. 
oocarpa with sodium carbonate and sodium bisulfite. Floresta e Ambiente 18(1):1-8
Waterman, P.G. y S. Mole. 1994. Methods in ecology. Analysis of phenolic plant metabolites. Blackwell Scientific publications. 237p. 2012. Evaluación de las características del fruto de huizache (Acacia farnesiana (L.) Willd.) para su posible uso en curtiduría o alimentación animal. Madera y Bosques 18(3):23-35. 